This item was submitted to Loughborough's Research Repository by the author.

Items in Figshare are protected by copyright, with all rights reserved, unless otherwise indicated.

\title{
Follow the leader! Direct and indirect flows of political communication during the 2013 Italian general election campaign
}

PLEASE CITE THE PUBLISHED VERSION

https://doi.org/10.1177/1461444813511038

\section{PUBLISHER}

Sage () The Author(s)

VERSION

AM (Accepted Manuscript)

\section{PUBLISHER STATEMENT}

This work is made available according to the conditions of the Creative Commons Attribution-NonCommercialNoDerivatives 4.0 International (CC BY-NC-ND 4.0) licence. Full details of this licence are available at: https://creativecommons.org/licenses/by-nc-nd/4.0/

\section{LICENCE}

CC BY-NC-ND 4.0

\section{REPOSITORY RECORD}

Vaccari, Cristian, and Augusto Valeriani. 2019. "Follow the Leader! Direct and Indirect Flows of Political Communication During the 2013 Italian General Election Campaign”. figshare.

https://hdl.handle.net/2134/28263. 


\title{
Follow the leader! Direct and indirect flows of political communication during the 2013 general election campaign
}

\author{
Cristian Vaccari and Augusto Valeriani \\ University of Bologna, Italy
}

\section{Introduction 1}

The 2013 Italian general election has been considered by many the first "Twitter Italian general election". Whether or not candidates' activity on the social networking site was relevant in determining the outcome of the race, most politicians flocked to this platform and the mainstream media paid very close attention to it.

Twitter is a micro-blogging service launched in 2006 that allows subscribers to post short messages of up to 140 characters. Users can sign up to others in order to have included in their own timeline messages (tweets) posted by all those they "follow", but can also search messages by keywords and "hashtags", i.e. words preceded by a "\#" in order to make all tweets containing them connected and more easily searchable. As of 2013 Twitter had more than 500 million registered users worldwide, 200 million of whom use it at least monthly. ${ }^{2}$ Unlike Facebook and the large majority of other social networking sites the "following" relationship on Twitter requires no reciprocation, which means that a user might follow accounts that don't follow the user back; with the exception of protected profiles, users do not

\footnotetext{
${ }^{1}$ This study was conducted thanks to the support of the Italian Ministry of Education "Future in Research 2012" initiative (project code RBFR12BKZH) for the project titled "Building Inclusive Societies and a Global Europe Online" (http://www.webpoleu.net). In accordance with Italian academic conventions, we specify that Cristian Vaccari wrote the paragraphs titled "Research Questions and Methodology", "Findings" and "Conclusions", and Augusto Valeriani wrote the paragraphs titled "Introduction" and "Literature Review". We thank the anonymous reviewers for their useful comments.

${ }^{2}$ See http://expandedramblings.com/index.php/march-2013-by-the-numbers-a-few-amazing-twitter-stats/ (accessed 3 September 2013).
} 
need the authorization of the accounts they follow, so that most content on Twitter is understood as public. Moreover, users can interact with one another by replying to someone else's tweet or by "mentioning" others (introducing in their message the addressee's screen name preceded by an “@”); finally, users can re-post ("retweet”) others' messages and in this way share them with all their own followers (in retweets the original message is preceded by “RT").

Italian Twitter users grew massively between 2010 and 2012, as total monthly users went from 1.4 million in December 2010 to 3.3 million in October $2012 .{ }^{3}$ Although Twitter is still only a niche channel compared with television and Facebook (the most popular social network in Italy, with 23.2 million users, out of 35 million Italians with internet access), it is becoming an important part of the contemporary Italian information ecosystem.

This article addresses how candidates develop networks of direct and indirect communication on Twitter. Politicians can communicate with citizens on Twitter in essentially two ways: directly, through messages that they broadcast to those users who "follow" them, and indirectly, to the extent that their supporters autonomously re-circulate these messages to their own followers that do not follow the politician in question.

Direct and indirect communication can be understood as targeting, respectively, a politician's "primary" and "secondary" audiences on Twitter. Politicians try to reach directly and deliberately those users that follow them when they post public status updates or engage with other politicians, journalists, or citizens with messages containing specific @user(s) tags that will be seen by most of their followers. ${ }^{4}$ This primary audience is composed by all the users who, by following a politician, can, at least potentially, be exposed to their public

\footnotetext{
${ }^{3}$ Available at http://vincos.it/osservatorio-facebook/ (accessed 2 June 2013).

${ }^{4}$ Twitter organizes messages so that, when a user mentions another user with the "@” key at the beginning of a message, only those users that follow both the sender and the mentioned user will see the tweet. Moreover, there are various ways to make these messages visible to all of one’s followers, for instance putting the "@” mentioned at the end of the message. Finally, all of a user’s messages, regardless of whether they begin with an “@”, can be seen by visiting her profile as long as it is not protected.
} 
messages. However, the tweets posted by politicians can also reach users that do not directly follow them if those who follow a politician decide to retweet one of her posts or to recirculate it in a partially or entirely altered form. We call this the secondary audience of politicians on Twitter to emphasize that it can be reached only if members of the primary audience re-broadcast the original message. This process can be described as indirect communication since it is mediated by choices that are outside politicians' control. While the direct route corresponds to what Bennett and Manheim (2006) have characterized as a "onestep flow of communication", the indirect route evokes an updated version of the two-step flow hypothesis (Katz and Lazarsfeld 1955).

It is important to emphasize that we focus essentially on potential audiences that could be reached by politicians through Twitter rather than on the conversations and interactions that actually occur therein. We refer to the "potential" for direct and indirect communication a necessary, but not sufficient premise for influence to occur - and assess the opportunities that Twitter affords politicians to reach and engage citizens during campaigns. To this end, we investigate the scale of the networks that politicians can directly or indirectly tap into and the nature and levels of activity of the nodes constituting them. Therefore the goal of the present study is to define how influence might work on Twitter during electoral campaigns rather than measuring the actual range of such influence.

In this article, we address these issues in the context of the Italian 2013 general election. After a review of the literature on social media and political communication, we evaluate the potential for both direct and indirect political communication via Twitter by analyzing the dynamics of the followings of national party and coalition leaders during the election campaign as well as the extent and intensity of the activities of these followers on the same platform. Our analysis leads us to conclude that social media may allow politicians to reach sizeable secondary audiences if and when the "vital middle" of users that lie between 
obscure lurkers and elusive entertainment stars decides to engage and distribute politicians' posts.

\section{Literature Review}

Various scholars have focused on the use of Twitter by politicians, parties, and citizens during and outside electoral campaigns. For instance, Golbeck et al. (2010) investigated the activity of U.S. Members of Congress and found that their main goal on Twitter was to promote themselves rather than engaging with citizens. Andrew Chadwick addressed the impact of social media on the production and consumption of political news and talked about a new political information cycle characterized by "the combination of news professionals" dominance and the integration of nonelite actors in the construction and contestation of news at multiple points" (2011: 3). Anstead and O'Loughlin (2011) analyzed patterns of citizen commentary of televised political programs and argued that the integration of viewing and live-commenting a program results in "a blurring of old and new processes to form new systems and practices" (2011: 441). Accordingly, Burgess and Bruns (2012: 23) analyzed the Australian 2010 election and argued that Twitter was important "not simply as a space in its own right, but as a means of disseminating information alternative to the mainstream media coverage and mass-mediated political discussion, and connecting such information to current debates". These studies indicate that Twitter is becoming a relevant arena for political communication and that it is tightly integrated with other channels.

Moreover, social media, and Twitter among them, may be more inclusive and resonating arenas of citizen communication than other digital channels of political communication such as websites. Studies of political websites have been premised on the theory that the "selective" nature of the internet - the fact that the web encourages users to 
choose the content they are exposed to and the people and organizations they engage with mostly increases opportunities for those who are already informed and engaged to become even more so, while having very little effect on everyone else (Bimber and Davis 2003). This led Margolis and Resnick (2000) to claim that the internet is conducive to "politics as usual" rather than a transformative environment. Social media may engender similar patterns by providing an avenue for the most informed and motivated citizens to reinforce their knowledge and attitudes, while leaving the uninterested mostly isolated from political prompts. Burges and Bruns (2012) described the users who were most active in political conservations on Twitter as a subculture of "political junkies". In his analysis of United States political blogs, Hindman (2009) found that attention and popularity tend to be concentrated among a few top-tier blogs and bloggers, while most others labor in total obscurity. A "missing middle" thus exists between the top and the bottom of the distribution, suggesting that online political communication is no less concentrated than in the mass media. If Twitter were to follow the same patterns, it would mostly attract highly engaged voters, offering them a viable avenue for self-expression and advocacy, but could not bridge gaps between them and the less interested citizens (Schlozman et al. 2010).

However, while some web 2.0 affordances still enable ample room for users' selection of content, which could thus lead uninterested citizens to simply avoid politics, others, such as retweets of political messages by one's nonpolitical contacts on social media, might allow opportunities for unintended exposure to political content. Moreover, the political twitterverse is not just about talking (writing) but also listening (reading). As suggested by Katie Crawford (2009), scholars' normative preference for "voice-as-democratic participation" has strongly influenced critical accounts of online activities, leading to a stigmatization of just-readers, negatively defined as "lurkers" (Kollock \& Smith 1996). On the contrary Crawford (2009) acknowledges that lurkers have always constituted the majority of 
users in most online spaces (Mason 1999; Nonnecke \& Preece 2003) and argues for a redefinition of lurkers as listeners: "listening more usefully captures the experience that many Internet users have. It reflects the fact that everyone moves between the states of listening and disclosing online; both are necessary and both are forms of participation" (2009: 527). Listeners give talkers the feeling to be heard by a larger community, thus motivating them to engage, and might also be "talkers" in other online or offline contexts, contributing to the spreading of information and ideas.

This brings us to the issue of influence and opinion leadership on Twitter. As already stressed, the aim of the present article is not to measure the actual extent of such influence, but to describe how such influence might work by analyzing the structure and the levels of activity of politicians' networks on Twitter. The function of person-to-person communication and the role of opinion leaders in influencing others and in circulating information was acknowledged for the first time by Katz and Lazarsfeld (1955) with their two-step flow theory, and Twitter could become another arena in which various types of personal influence and opinion leadership develop. As noted by Marwich and boyd (2011) and by Page (2012), saying that Twitter is a "conversational" environment, and that newcomers and listeners are not completely passive, does not mean arguing that participation and influence opportunities are equally distributed. In their analysis of the 2010 United States midterm election, Vaccari and Nielsen (2013) found that most politicians fail to achieve large-scale direct communication with citizens on social media in spite of the large number of voters who use these platforms. On the other hand, even those who do amass large audiences online are not necessarily influential on social media. Cha et al. (2010) warn against "the million follower fallacy" that can result if we equate influence with followers. Celebrities, such as athletes, musicians, television stars, but also top politicians and news persons, usually have the largest audiences on Twitter. However, the number of followers one account has might be a first 
indicator, but it is definitely not an exhaustive measure of influence. Although the opportunity to directly address large audiences through social media accrues to very few politicians and is an increasingly coveted goal for some of them, drawing large crowds online does not necessarily translate into influence, especially if one's followers are unwilling or unable to redistribute messages to substantial numbers of their own followers.

A broader understanding of political communication on Twitter should thus not be limited to the primary audiences that one can address directly, but must also include the secondary ones that can be reached indirectly through the primary audiences-considering not only the activity of politicians, but also their followers' activity and numbers of followers. As Bode at. al. (2011) argued in analyzing the 2010 U.S. mid-term elections, "unless followers of candidates are engaging on Twitter with others beyond the candidate community, social media campaigns may not be as successful in reaching less active and interested populations." Indirect communication on social media is the result of low-threshold activities (Chadwick 2009) by users who follow politicians and share (or retweet) messages, pictures or videos that they received from politicians. Consequently, these followers' personal networks on social media could highly expand a candidate's reach beyond her primary audiences.

Thus, in analyzing politicians' communication on social media, we should not just focus on follower/following patterns (e.g. Krishnamurthy et al. 2008). Even ordinary users sometimes manage to gain niches of authority (Cha et al. 2010) and acquire "micro-celebrity" status (see Senft 2008; Page 2012). However, it is still unclear whether citizens, microcelebrities and "peripheral" politicians can really compete, in terms of the audiences they can reach, with "power users" like show-business personalities or figures that are highly visible in the politics-media ecosystem.

\section{Research Questions and Methodology}


Our study addresses four research questions on the potential for direct and indirect political communication on Twitter in the 2013 Italian general election. In order to answer these questions, we analyze the size and activity of the primary and secondary Twitter audiences of the main Italian national party leaders.

First, we aim to evaluate the size of the followings of national party and coalition leaders during the campaign. These patterns will allow us to assess the potential for direct communication by political leaders, i.e., how many people are targeted by the content they post on Twitter-their potential primary audiences.

Secondly, we aim to comprehend the extent and intensity of the Twitter activities of politicians' followers. In particular, we investigate whether most of these users are active and frequent participants to Twitter conversations or they are mostly "listeners" (Crawford 2009) to discussions (political or otherwise) animated by others. We also aim to find out how many people follow these users, which leads us to the question of indirect communication, i.e., how extensive the network is that politicians can mobilize via their supporters' connections-their potential secondary audiences.

Thirdly, we analyze the relationship between the first and the second variables, that is, whether politicians who have many followers also have the most active ones, in which case inequalities rooted in direct communication would be reinforced by indirect communication.

Fourthly, we address the distribution of Twitter activity and followers among politicians' followers to assess the extent to which social media engagement is an egalitarian or uneven terrain among these users. We also aim to understand what characteristics distinguish the most active users that follow political leaders-in particular, whether they can be defined as elites or as ordinary citizens, and how likely they are to pay attention to Italian politicians' digital messages. 
We identified the national party leaders whose followers we were going to study based on public opinion polls. According to most surveys, in January 2013 five main coalitions were attracting the vast majority of support: the center-left, led by the Democratic Party, the center-right, led by the People of Freedom, the center, led by a civic list in support of Prime Minister Mario Monti; the Five Star Movement, led by former comedian Beppe Grillo (who did not run for office), and the radical left, which coalesced into a unity list named Civil Revolution. For each coalition, we consider the leader of the main party and that of its largest junior ally (with the exception of Five Star Movement which ran on its own). For the People of Freedom party we included both its formal secretary, Angelino Alfano, and its founder and president, Silvio Berlusconi, because, in spite of official party statements that Alfano would become Prime Minister in case of victory, it was Berlusconi that led the campaign. (Also, Berlusconi did not have an official personal Twitter account, but only an account run by his “digital volunteers".) For the radical left coalition, we included the leader of Italy of Values, a party that fielded candidates under the banners of Civil Revolution, because it was the biggest among the parties that coalesced in this cartel. Therefore, we analyzed the accounts of the following ten leaders: ${ }^{5}$

- Center-left

o Pierluigi Bersani (Democratic Party, Twitter screen name @pbersani)

o Nichi Vendola (Left, Ecology and Freedom, @nichivendola)

- Center-right

o Angelino Alfano (People of Freedom, @angealfa)

o Silvio Berlusconi (People of Freedom, @berlusconi2013)

o Roberto Maroni (Northern League, @maroni_leganord)

\footnotetext{
5 We did not include the list "Acting to stop the decline", led by journalist Oscar Giannino, which polled around $2 \%$ and ended up getting around $1 \%$ of the votes. Nonetheless, Giannino had a rather significant following on Twitter (almost 73,000 by Election Day).
} 
- Center

o Mario Monti (Civic Choice with Monti for Italy, @senatoremonti)

o Pierferdinando Casini (Union of Center, @pierferdinando)

- $\quad$ Five Star Movement

o Beppe Grillo (Five Star Movement, @beppe_grillo)

- Civil Revolution

o Antonio Ingroia (Civil Revolution, @antonioingroia)

o Antonio Di Pietro (Italy of Values, @idvstaff).

We then collected three types of data on these profiles.

First, to understand the dynamics of their followings on Twitter, we collected data on the number of followers that each of them had on every day between 23 December 2012 and 23 February 2013, the last day before the election was held. ${ }^{6}$

Secondly, to assess the levels of Twitter activity of these leaders' followers, we collected data through an application that queried Twitter's public API. ${ }^{7}$ We retrieved these followers' screen names, the number of all tweets they had posted since they had created their profile, ${ }^{8}$ the number of accounts they followed, and the number of accounts that

${ }^{6}$ The data are publicly available and were retrieved from the website http://twittercounter.com/TweetCount (accessed 4 April 2013).

${ }^{7}$ API stands for "Application Programming Interface" and is a set of instructions and protocols that enables users to access a web-based software application. Twitter's API (https://dev.twitter.com/) allows researchers to retrieve public Twitter messages as well as relevant "metadata" such as the identifier of the user who posted them, date, location, language, and so forth. It also allows to run queries, such as those we used for this study, on the users that follow certain accounts.

${ }^{8}$ When a user has never posted any tweet, the API returns an empty cell; however, the same result is obtained when a user has protected her tweets, enabling only her followers to see them. Thus, when an empty cell appears in our dataset, we cannot automatically determine whether this is due to the former (no tweets ever sent) or the latter (protected tweets). To adjudicate between these two hypotheses, we randomly selected 500 accounts that had returned empty cells and directly retrieved their accounts on Twitter. Only 23 , or about $5 \%$ of the total, turned out to be protected accounts, whereas all the remaining were indeed accounts that had yet to send a single tweet. We thus decided to treat all empty cells as ' 0 ' rather than missing values, knowing that this choice leads us to slightly underestimate the total number of tweets posted by the users we are studying because it does not account for the unknowable number of tweets of those who made their accounts private. However, the bias resulting from treating all these values as missing would be much greater because a large number of users who have actually never posted any messages would be excluded from our analysis, strongly inflating its results. 
followed them. Our application automatically extracted this information for all followers of the accounts we studied in batches (groups) of 5,000 accounts for each query, so that, for instance, collecting data on 15,000 followers required three subsequent queries. However, sporadic technical failures implied that a few queries returned fewer than 5,000 accounts, or that some retrieval procedures returned no data. Although the accounts that were occasionally not retrieved were most likely determined randomly (since they were the result of occasional problems in the communication between the application we were using and the Twitter API rather than any systematic factors), we minimized the impact of these errors by retrieving the data at least twice for all leaders between 11 and 23 February (the day before the election). This procedure allowed us to retrieve information on 2,078,265 accounts, or $95 \%$ of the $2,186,972$ which is the sum of the numbers of followers that each leader had at the end of the campaign. ${ }^{9}$ The number of unique accounts, once all duplicates were removed, was $1,281,217$. This means that about $40 \%$ of the users who followed one national leader also followed at least another one.

Thirdly, we aim to analyze the characteristics of the followers of politicians that offer the greatest potential for indirect communication because they have the most followers themselves, and they can turn them into secondary audiences for politicians if they recirculate politicians' messages. To do this, we selected those followers of national party leaders that had at least 10,000 followers, for a total of 1,148 accounts. We then retrieved these users' public Twitter profiles and, based on information provided therein and other that could be found through internet searches, we classified them as: (a) individuals versus organizations;

\footnotetext{
${ }^{9}$ In particular, we could cover $100 \%$ of the followers of Alfano, Berlusconi, and Casini, more than $95 \%$ of those of Di Pietro, Ingroia, Maroni, Monti, and Vendola, and more than $90 \%$ of those of Bersani and Grillo. Coverage rates are essentially a function of the number of followers and account has, because the accounts with larger followings required more retrievals of 5,000-user batches, which statistically increased probabilities of error, resulting in a certain number of missing accounts even after two full retrieval cycles. In the cases of Alfano and Berlusconi, we actually have slightly more total users than the number of their followers on election eve. This is most likely because some of their users stopped following them between our first and second retrieval cycles, so they remained in our dataset even if they were no longer following these politicians right before the vote. Most likely, these situations apply to a very limited portion of all politicians' followers.
} 
(b) male versus female; (c) Italian versus foreign. We also coded their professional status as (d) journalists or media organizations; (e) politicians and political organizations, or trade unions and unionists; (f) bloggers or blogs; (g) political consultants and professionals, or companies providing these services, or academics; (h) belonging to the realms of sport, entertainment, arts, and show-business; (i) businessmen or companies; (j) involved in the world of technology; (k) charities, NGOs, and public interest groups; (l) comedians or satire publications. These categories were not mutually exclusive, as some users could conceivably fulfill more than one of these roles at a given time.

\section{Findings}

The potential for direct communication between political leaders and Twitter users depends on the size of leaders' primary audiences, that is, the number of followers they accumulated throughout the campaign. As Table 1 shows, these primary audiences on Twitter grew substantially during the two months before the vote, from 1.5 to almost 2.2 million (+44\%). Although some of this expansion might be related to the increase of Italians that started using Twitter during that period, a large part of it is likely due to the growing interest in the campaign among Italians who use this social media platform, not least due to vast media coverage of it. The data also suggest that there is no relationship between the election results and politicians' initial or final amounts of followers, nor their growth rates: for instance, the People of Freedom won $21.5 \%$ of the popular vote, but its two leaders combined for only $6 \%$ of the total followers; the Democratic Party achieved $25.4 \%$ of the popular vote, but its leader had only $12 \%$ of the total followers; by contrast, the leader of the Five Star Movement had many more followers, as a percentage of the total, than votes: $42 \%$ versus $25.5 \%$; the radical left and the center also had larger shares of followers than votes. This pattern suggests that 
competition for Twitter audiences did not reflect inequalities in other resources, such as media visibility and organization, as has often been found for other online platforms (Margolis and Resnick 2000). It seems that Twitter allowed some party leaders to build followings that are proportionally much larger than their vote shares would suggest. If it depended solely on politicians' efforts to engage with citizens on Twitter, this pattern might be seen as contributing to widening and to some extent leveling the competitive playing field between more and less resourceful political actors. It may also be, however, that Twitter disproportionately attracts citizens who tend to favor some politicians and parties over others. Indeed, a survey of Italian Twitter users who talked about the election (Vaccari et al. 2013) found that they tended to be much more left-leaning and radical than the rest of the population. Although we remain cautious about the root causes of the distribution that we observed, evidently some parties were in a better competitive position on Twitter than on the mass media, which mostly covered the major parties and their leaders. This seems to be particularly the case for Grillo, whose Five Star Movement placed a very strong emphasis on the internet and ostentatiously avoided exposure on the mass media (Bordignon and Ceccarini 2013). Grillo, however, might be a deviant case because he can use his popularity as a comedian to attract broad audiences on the web even without media coverage. In order to account for Grillo's outlier status, the bottom row of Table 1, as well as those that will follow, shows descriptive statistics both including and excluding his followers.

\section{[Table 1 about here]}

As we highlighted in the previous paragraph, the potential for direct communication to a politicians' primary audiences should be conceptually distinguished from the potential for indirect communication through that politician's primary audience. In order to assess this 
latter asset, Table 2 shows summarizes the levels of activity and the sizes of the publics of Twitter users who followed national party leaders. Central tendencies hardly suggest an intensely engaged public: the median follower of political leaders in Italy only follows 28 accounts, is followed by just 3 other users, and has only posted 4 tweets since opening her account. Averages are slightly higher, with users following 154 accounts, being followed by 113 other users, and having tweeted 228 times since landing on this social media platform. ${ }^{10}$ Numbers slightly increase if we exclude Grillo's followers, but even that is hardly the portrait of a powerful message multiplier, especially considering that the data combine activities related to all sorts of nonpolitical domains. If we were to isolate only the political uses of Twitter, the figures would be dramatically lower.

\section{[Table 2 about here]}

The data also reveal interesting differences between the audiences of different national leaders. The two politicians with the smallest numbers of followers - Ingroia and Maroni also have, on average, the most active followers in terms of the number of accounts they follow, the ones that follow them, and the number of messages that they posted. ${ }^{11}$ By contrast, Grillo, who had by far the largest number of followers, also had the least engaged followers by all available measures, followed by Vendola, Bersani, Monti and Di Pietro, who also attracted substantial audiences. Thus, there seems to be a rather systematic negative correlation between the size of a politician's Twitter audience and the level of activity, political or otherwise, of his followers. While this phenomenon is particularly pronounced for Grillo,

\footnotetext{
10 These figures are consistent with a market research conducted in October 2012 based on a sample of 36 million Twitter accounts, which found that the mean number of followers is 208 and that of accounts followed is 102, but more than four-fifths have fewer than 50 followers and one-fourth have never been used (see http://www.beevolve.com/twitter-statistics/\#e1, accessed 26 April 2013).

${ }^{11}$ Followers of Berlusconi's account follow an exceedingly high number of accounts, a finding on which we do not elaborate in light of the fact that this was not his official account. Speculations have been made, however, that at least part of the followers of this account had been purchased from social media marketing agencies.
} 
Table 3 shows that the pattern occurs among all leaders and across all activity measures. Correlation coefficients between audience size and activities are negative in all cases and are significant in three out of six occasions. If we exclude Grillo - an outlier due to the particularly low activity of his followers - results do not change dramatically and if we exclude Berlusconi - an outlier in terms of the number of accounts followed by his followers, as well as the only non-official account in our sample - all correlations become stronger. A law of diminishing returns seems to be operating by which the more followers a politician accumulates, the less active they tend to be. Leaders with smaller followings probably have audiences that are more committed to them and more active on Twitter in general, whereas more popular politicians attract large amounts of users who prefer to listen than to talk and may follow that particular leader out of passing curiosity rather than genuine interest.

\section{[Table 3 about here]}

The data suggest that there are wide disparities not only among different leaders, but also among their followers. This is revealed, for example, by the large differences between mean and median scores in Table 2. Another way to address this issue is to look at how many of these followers are utterly inactive on Twitter, and how many are instead particularly engaged to the point that they can be considered "power followers". We define inactive users as those who have no followers or have not tweeted a single message since they opened their account, and power followers as those who have at least 1,000 followers or have tweeted at least 1,000 times.. Table 4 shows that as many as $19 \%$ of the accounts in our sample had no followers and $22 \%$ had never tweeted once when we collected the data. ${ }^{12}$ By contrast, only 0.6\% had more than 1,000 followers and just $4 \%$ had sent more than 1,000 tweets. Taken

\footnotetext{
${ }^{12}$ Some of these accounts may had just been opened when we collected our data, and their activity may thus have increased since then.
} 
together, the data reported in Tables 2 and 4 suggest that a very uneven dynamic is in place by which a large amount of politicians' followers are entirely inactive (or have never really accessed their accounts, or might even be machine-generated profiles), half of them are barely active, and only a tiny minority of no more than five percent intensely engage with Twitter. Thus, if they want to achieve large secondary audiences, politicians must rely either on their very few "power followers", who may reach substantial audiences with one single retweet, or on smaller-scale, distributed amplification by a large number of the $99.4 \%$ of their followers who are followed by fewer than one thousand users.

\section{[Table 4 about here]}

Consistently with previous findings, the politicians with the fewest followers also have the lowest percentages of inactive followers and the highest percentages of active ones. By contrast, almost one-third of Grillo's followers have never sent a tweet and only one in 200 is followed by at least 1,000 other users. Thus, the law of diminishing returns that we have identified for central tendencies also applies to how many active and inactive followers each politician has.

Finally, we focus on the characteristics of the most followed followers, i.e., the 1,148 followers of national leaders that had more than 10,000 followers. ${ }^{13}$ Since these users have the greatest potential to reach large audiences, they could be the most powerful channels of indirect communication for political leaders to the extent that they share politicians' messages with their own numerous followers, whom they would thus turn into politicians' secondary audiences. Understanding the characteristics of these "top power followers" will

\footnotetext{
13 In our dataset, a total 2,730 cases had more than 10,000 followers, but unique accounts were 1,148. Of the original 2,730 cases, 184 followed Alfano (7\% of the total), 174 Berlusconi (6\%), 365 Bersani (13\%), 259 Casini (9\%), 214 Di Pietro (8\%), 478 Grillo (18\%), 107 Ingroia (4\%), 85 Maroni (3\%), 352 Monti (13\%), and 512 Vendola (19\%).
} 
allow us to assess (a) to what extent they can be expected to really pay attention to messages from Italian party leaders; (b) whether they are likely to be effective channels of indirect communication, by allowing politicians to reach audiences that usually ignore politics; (c) whether they can be characterized as elites or ordinary citizens, and thus the degree to which the potential for indirect communication on Twitter is distributed in a way that resembles or challenges offline power structures. Table 5 shows the main characteristics of Italian politicians' "top power followers". 14

\section{[Table 5 about here]}

Top power followers of Italian politicians are predominantly male individuals, and only less than two-thirds are Italian. It is difficult to imagine that foreign users may be interested in the tweets of Italian politicians and the situation of the country, with a few exception such as journalists. It is thus even more unlikely that these users may retweet Italian politicians' messages to their followers. In terms of the social roles of these users, the categories that are most common are celebrities $33 \%$ of all accounts, not including comedians and satiric accounts that comprise another 3\%) and journalists and news organizations (22\%). A second group of accounts includes those of corporate entities and consultants (14\%, with an another $4 \%$ specializing in technology) and those of politicians and political organizations (12\%, not including political professionals, experts and academics that account for another 3\%). Bloggers constitute $7 \%$ and all other categories are residual.

Celebrities may offer politicians some potential for indirect communication because their followers may include many citizens who are not particularly interested in politics, thus

\footnotetext{
14 The table is based on 1,119 cases rather than 1,148 because 29 accounts could no longer be accessed on Twitter when we conducted this analysis, about two months after the data on politicians' followers had been retrieved. These accounts may have changed their usernames, may have been suspended or banned by Twitter, or may have voluntarily left Twitter.
} 
functioning, in Freelon and Karpf's (2013) terminology, as "bridging elites", allowing political messages to reach citizens who are not interested enough to pay attention to the political establishment on social media. To the extent that celebrities follow party leaders and share content originally posted by them, their social media presence may thus resemble the role played by talk shows and "infotainment" television programs in allowing low-interest voters to acquire political information that they would not normally seek (Delli Carpini and Williams 2001) and bypass the opportunity to avoid political messages afforded by high-choice media (Prior 2007). However, only two-thirds of the celebrities among our top power followers were Italian, and foreign celebrities comprise one in ten of all this elite population. It seems unlikely that U.S. rap singers and European deejays - categories that loomed large among the celebrities in our population - will ever pay attention to what Italian politicians say on Twitter. They probably follow these accounts as part of social media marketing strategies that often suggest to follow popular accounts in hope to be followed back. This logic may also apply to the many corporate and technology-related accounts, most of which are located outside of Italy.

Journalists and bloggers, however, comprise almost as many top power followers as celebrities and are more likely to function as conduits of politicians' social media messages. Both play an important role in the broader political information cycle (Chadwick 2011) and four in five journalists in this group were Italian. This finding suggests that journalistic mediation is still relevant in the flow of political information and communication on Twitter (Hermida 2010). The 7\% of top power followers that are bloggers constitutes the only group that could be characterized as non-elite actors. However, many of them are elite bloggers (Hindman 2009), highly visible in the Italian media system and often co-opted by mainstream media or political organizations. 
A final interesting aspect involves the large number of high-profile politicians and political organizations who follow political leaders. Apart from the fact that almost one-third of them are not Italian - revealing patterns of transnationalization of online political communication - the fact that prominent politicians follow each other suggests that Twitter also functions as a channel of intra-elite conversation. Politicians often use Twitter to engage in mutual attacks or discussions, knowing that their statements will be read by journalists who follow them as well as by their and their opponents' followers. This network of connections among politicians signals their attempt to disintermediate from mass media routines and constraints while maintaining journalists' attention.

Before discussing the implications of our findings, a few limitations of our study need to be acknowledged. First, our analysis focuses on the overall Twitter activities of politicians' followers rather than on specific measures of their political engagement on social media. In all likelihood, reading and sharing political messages only constitutes a fraction of overall Twitter usage. Moreover, our data measure the potential for direct and indirect communication on Twitter, not the extent to which such potential is actually realized. The distinction between direct and indirect communication, while being useful to differentiate between dynamics that politicians can and cannot control, is to some extent a simplification of reality, as users can take multiple roles at different times, for instance by receiving a tweet from a politician they follow, disseminating it to their followers, and then subsequently being involved in a conversation about it with those to whom they distributed the message. Also, not all indirect political communication enabled by a social networking site is bounded within that space only: in a hybrid media environment, a citizen may relay content that she first saw on Twitter by reposting it on Facebook or other online environments, or by talking about it in her offline networks of interpersonal discussion. Finally, our study is limited by its focus on a single country, with particular cases such as Grillo - a celebrity turned politician, the leader of 
a self-described leaderless movement that has made the web the centerpiece of its campaign, and the curator of the most popular blog in the country - and Berlusconi - a television tycoon who has dominated political communication through the mass media for two decades and who, for that reason, has largely neglected using the internet - suggesting that comparative scrutiny of our findings is required.

\section{Conclusions}

Our analysis of more than two million Twitter followers of the main Italian party leaders during the 2013 general election has shed light on the potential for direct and indirect communication that Twitter affords politicians. We have shown that the vast majority of Twitter users who follow party leaders in Italy are inactive and have a very limited number of followers, and cannot therefore function as effective vehicles for wide-ranging indirect communication between politicians and citizens. The data have also revealed very profound inequalities in the activities and popularity of these Twitter users, with power-law distributions by which tiny minorities produce the vast majority of tweets and gather most of the followers. Thus, while the majority of politicians' followers can be described as "lurkers", or "listeners", or perhaps even "deaf" to these messages having abandoned their accounts, only a few have the potential to reach large numbers of followers. Moreover, among the top tier of elite users who have more than 10,000 followers, a plurality turned out to be celebrities and a vast number consisted of individuals or organizations that are already extremely visible in the media-politics ecosystem.

From the standpoint of political competition, our findings suggest moderately optimistic conclusions. The number of users who followed politicians did not correlate with their levels of electoral support, as outsiders such as Grillo and minor party leaders such as 
Vendola gathered large audiences. Moreover, the hierarchies of potential influence on Twitter have turned out to be more complex than indicated by the simple number of followers a politician has. The negative correlation between a users' following and his followers' activity and popularity suggests that Italian politicians face a trade-off between having a large audience of lukewarm listeners and having a smaller but more engaged public. High numbers do not necessarily equal strong engagement and, in turn, wider reach.

Our findings suggest that the most viable channels for indirect communication - from politicians to their primary audiences, and through them to secondary audiences - might be found in that middle that Hindman (2009) found to be missing in his study of political blogs. That is, among those Twitter users who are more than minimally popular within the platform, roughly located above the median levels of activity and popularity, but who are not as popular as the elusive elite users. Rather than a missing middle, a "vital middle" seems to exist on Twitter where each individual contribution does not reach large audiences, but aggregation of many small-scale endeavors might lead to wide-ranging diffusion of political messages.

\section{References}

Anstead N and O'Loughlin B (2011) The Emerging Viewertariat and BBC Question Time:

Television Debate and Real-Time Commenting Online. The International Journal of Press/Politics 16(4): 440-462.

Bennett WL and Manheim J.B (2006) The One-Step Flow of Communication. The ANNALS of the American Academy of Political and Social Science 608(1), 213-232.

Bimber B and Davis R (2003) Campaigning Online: The Internet in US elections. Oxford, New 
York: Oxford University Press.

Bode L, Dalrymple K and Shah D (2011) Politics in 140 Characters or Less: Campaign Communication, Network Interaction, and Political Participation on Twitter. Paper presented at the annual meeting of the American Political Science Association, Seattle (WA 1-4) September 2011.

Bordignon F and Ceccarini L (2013) Five Stars and a Cricket. Beppe Grillo Shakes Italian Politics. South European Politics \& Society. Epub ahead of print 21 February 2013. DOI:10.1080/13608746.2013.775720.

Burgess JE and Bruns A (2012) (Not) the Twitter election: The dynamics of the \#ausvotes conversation in relation to the Australian media ecology. Journalism Practice 6(3): 384-402.

Cha M, Haddadi H, Benevenuto F and Gummadi KP (2010). Measuring User Influence in Twitter: The Million Follower Fallacy. Proceedings International AAAI Conference on Weblogs and Social Media (ICWSM) Washington DC 23-26 May 2010.

Chadwick A (2009) Web 2.0: New Challenges for the Study of E-Democracy in an Era of Informational Exuberance. I/S: Journal of Law and Policy for the Information Society 5(1): 941.

Chadwick A (2011) The Political Information Cycle in a Hybrid News System: The British Prime Minister and the 'Bullygate’ Affair. International Journal of Press/Politics, 16(1): 3-29. 
Crawford K (2009) Following you: Disciplines of listening in social media. Continuum: Journal of Media \& Cultural Studies 23 (4): 525-535.

Delli Carpini M and Williams B (2001) Let Us Infotain You: Politics in the New Media Environment. In Bennett L and Entman R (eds.) Mediated Politics: Communication in the Future of Democracy. Cambridge: Cambridge University Press, pp. 160-181.

Freelon D and Karpf D (2013) Of Big Birds and Bayonets: Hybrid Twitter Interactivity in the 2012 Presidential Debates. Paper presented at the annual meeting of the American Political Science Association, Chicago (IL) 29 August - 1 September 2013.

Golbeck J, Grimes JM and Rogers A (2010) Twitter use by the U.S. Congress. Journal of the American Society for Information Science and Technology 61(8): 1612-1621.

Hermida A (2010) Twittering the News: The Emergence of Ambient Journalism. Journalism Practice 4(3): 297-308.

Hindman M (2009) The Myth of Digital Democracy. Princeton: Princeton University Press.

Katz E and Lazarsfeld P (1955) Personal influence: The part played by people in the flow of mass communication. Glencoe, NY: Free Press.

Kollock P and Smith M (1996) Managing the virtual commons: Cooperation and conflict in computer communities. In Herring S (ed.) Computer-mediated communication: Linguistic, social, and crosscultural perspectives. Amsterdam: John Benjamins, pp. 109-128. 
Krishnamurthy B, Gill P and Arlitt, M. (2008) A few chirps about Twitter. Proceedings of the First Workshop on Online Social Networks WOSP '08, Seattle (WA) 18 August 2008.

Margolis M and Resnick D (2000) Politics as Usual: The Cyberspace "revolution." Thousand Oaks, CA: Sage Publications.

Marwick AE and boyd D (2011) I tweet honestly, I tweet passionately: Twitter users, context collapse, and the imagined audience. New Media \& Society 13(1): 114-133.

Mason B (1999) Issues in virtual ethnography. In Buckner K. (ed.) Esprit 13: Workshop on ethnographic studies in real and virtual environments: Inhabited information spaces and connected communities. Edinburgh: Queen Margaret College, pp. 32-37.

Nonnecke B and Preece J (2003) Silent participants: Getting to know lurkers better. In Lueg C and Fisher D (eds.) From Usenet to CoWebs: interacting with social information spaces. Amsterdam: Springer, pp. 110-132.

Page R (2012) The linguistics of self-branding and micro-celebrity in Twitter: The role of hashtags. Discourse \& Communication 6(2): 181-201.

Prior M (2007) Post-Broadcast Democracy: How Media Choice Increases Inequality in Political Involvement and Polarizes Elections. New York: Cambridge University Press.

Schlozman KL, Verba S and Brady HE (2010) Weapon of the Strong? Participatory Inequality 
and the Internet. Perspectives on Politics 8(2): 487-509.

Senft T (2008) Camgirls: Celebrity and Authenticity in the Age of Social Networks. New York: Peter Lang.

Vaccari C \& Nielsen RK (2013) “What Drives Politicians' Online Popularity? An Analysis of the 2010 U.S. Midterm Elections." Journal of Information Technology \& Politics 10(2) 202-222.

Vaccari C, Valeriani A, Barberá P, Bonneau R, Jost J, Nagler J, \& Tucker J (2013). “Social Media and Political Communication: A survey of Twitter users during the 2013 Italian general election." Rivista Italiana di Scienza Politica 43(3). 
Table 1 - Number of Followers of the Ten Main National Party Leaders, 12/23/2012 $2 / 23 / 2013$

\begin{tabular}{|c|c|c|c|c|c|}
\hline Politician & $12 / 23 / 2012$ & $1 / 23 / 2013$ & $2 / 23 / 2013$ & $\%$ & Growth \\
\hline Alfano & 50,525 & 65,796 & 71,583 & $3 \%$ & $+42 \%$ \\
\hline Berlusconi & 10,484 & 65,001 & 67,240 & $3 \%$ & $+541 \%$ \\
\hline Bersani & 184,947 & 238,650 & 270,339 & $12 \%$ & $+46 \%$ \\
\hline Casini & 84,984 & 99,179 & 105,113 & $5 \%$ & $+24 \%$ \\
\hline Di Pietro & 146,324 & 156,792 & 161,854 & $7 \%$ & $+11 \%$ \\
\hline Grillo & 768,710 & 836,073 & 916,252 & $42 \%$ & $+19 \%$ \\
\hline Ingroia & (Not present) & 20,332 & 35,658 & $2 \%$ & $\mathrm{~N} / \mathrm{A}$ \\
\hline Maroni & 10,246 & 16,842 & 21,062 & $1 \%$ & $+106 \%$ \\
\hline Monti & (Not present) & 192,887 & 229,432 & $10 \%$ & $\mathrm{~N} / \mathrm{A}$ \\
\hline Vendola & 265,663 & 289,831 & 308,439 & $14 \%$ & $+16 \%$ \\
\hline Total & $1,521,883$ & $1,981,383$ & $2,186,972$ & $100 \%$ & $+44 \%$ \\
\hline Total w/out Grillo & 753,173 & $1,145,310$ & $1,270,720$ & $58 \%$ & $+69 \%$ \\
\hline
\end{tabular}


Table 2 - Summary Statistics of Twitter Activity of the Followers of Political Leaders

\begin{tabular}{|c|c|c|c|c|c|c|c|}
\hline & \multicolumn{3}{|c|}{ Following } & \multirow{2}{*}{$\begin{array}{l}\text { Tweets } \\
\text { Median }\end{array}$} & \multicolumn{2}{|c|}{ Followers } & \multirow[b]{2}{*}{$N$} \\
\hline & Mean & Median & Mean & & Mean & Median & \\
\hline Alfano & 261 & 102 & 472 & 24 & 221 & 15 & 72,091 \\
\hline Berlusconi & 865 & 581 & 386 & 12 & 204 & 10 & 67,250 \\
\hline Bersani & 186 & 48 & 345 & 8 & 243 & 7 & 248,503 \\
\hline Casini & 282 & 94 & 455 & 16 & 445 & 13 & 105,915 \\
\hline Di Pietro & 220 & 56 & 371 & 8 & 257 & 7 & 157,524 \\
\hline Grillo & 109 & 25 & 177 & 3 & 74 & 3 & 852,988 \\
\hline Ingroia & 330 & 112 & 787 & 52 & 514 & 21 & 34,558 \\
\hline Maroni & 324 & 106 & 601 & 36 & 355 & 18 & 20,192 \\
\hline Monti & 167 & 49 & 389 & 12 & 167 & 8 & 219,870 \\
\hline Vendola & 203 & 52 & 379 & 8 & 244 & 8 & 299,365 \\
\hline All unique users & 154 & 28 & 228 & 3 & 113 & 4 & $1,281,217$ \\
\hline All users w/out Grillo's & 220 & 43 & 317 & 6 & 170 & 6 & 722,433 \\
\hline
\end{tabular}


Table 3 - Correlation Between Numbers of Politicians' Followers and their Mean and Median Levels of Twitter Activity (Pearson's $\boldsymbol{R}$ coefficients, $\boldsymbol{p}$ in parentheses)

\begin{tabular}{lccc}
\hline & All Leaders & Without Grillo & Without Berlusconi \\
\hline Mean following & $-.461(.180)$ & $-.485(.186)$ & $-.842^{* *}(.004)$ \\
Median following & $-.342(.334)$ & $-.396(.292)$ & $-.803^{* *}(.009)$ \\
Mean followers & $-.658^{*}(.039)$ & $-.513(.158)$ & $-.722^{*}(.028)$ \\
Median followers & $-.732^{*}(.016)$ & $-.811^{* *}(.008)$ & $-.761^{*}(.017)$ \\
Mean tweets & $-.734^{*}(.016)$ & $-.687^{*}(.041)$ & $-.777^{*}(.014)$ \\
Median tweets & $-.578(.080)$ & $-.728^{*}(.026)$ & $-.624(.073)$ \\
$N$ & 10 & & \\
\hline
\end{tabular}

Note: $* \mathrm{p} \leq .05^{* *} \mathrm{p} \leq .01^{* * *} \mathrm{p} \leq .001$ 
Table 4 - Politicians' Followers with 0 and 1,000 Followers and Tweets

\begin{tabular}{|c|c|c|c|c|c|c|c|c|}
\hline & \multicolumn{2}{|c|}{ O Followers } & \multicolumn{2}{|c|}{0 Tweets } & \multicolumn{2}{|c|}{ 1,000 Followers } & \multicolumn{2}{|c|}{ 1,000 Tweets } \\
\hline & Total & $\%$ & Total & $\%$ & Total & $\%$ & Total & $\%$ \\
\hline Alfano & 6,334 & $9 \%$ & 10,763 & $15 \%$ & 1,154 & $1.6 \%$ & 6,426 & $9 \%$ \\
\hline Berlusconi & 3,968 & $6 \%$ & 9,273 & $14 \%$ & 866 & $1.3 \%$ & 4,562 & $7 \%$ \\
\hline Bersani & 30,452 & $12 \%$ & 57,002 & $23 \%$ & 2,595 & $1.0 \%$ & 14,908 & $6 \%$ \\
\hline Casini & 10,135 & $10 \%$ & 18,741 & $18 \%$ & 1,625 & $1.5 \%$ & 8,667 & $8 \%$ \\
\hline Di Pietro & 19,471 & $12 \%$ & 35,518 & $23 \%$ & 1,553 & $1.0 \%$ & 10,075 & $6 \%$ \\
\hline Grillo & 175,610 & $21 \%$ & 266,547 & $31 \%$ & 4,006 & $.5 \%$ & 26,797 & $3 \%$ \\
\hline Ingroia & 1,813 & $5 \%$ & 3,602 & $10 \%$ & 768 & $2.2 \%$ & 4,642 & $13 \%$ \\
\hline Maroni & 1,698 & $8 \%$ & 2,670 & $13 \%$ & 458 & $2.3 \%$ & 2,288 & $11 \%$ \\
\hline Monti & 29,768 & $14 \%$ & 41,598 & $19 \%$ & 2,499 & $1.1 \%$ & 15,487 & $7 \%$ \\
\hline Vendola & 33,896 & $11 \%$ & 67,446 & $23 \%$ & 3,418 & $1.1 \%$ & 19,186 & $6 \%$ \\
\hline All unique users & 239,834 & $19 \%$ & 368,477 & $29 \%$ & 8,275 & $.6 \%$ & 49,525 & $4 \%$ \\
\hline All users w/out Grillo's & 101,512 & $14 \%$ & 167,144 & $23 \%$ & 6,648 & $.9 \%$ & 38,834 & $5 \%$ \\
\hline
\end{tabular}


Table 5 - Characteristics of the Followers of Political Leaders Who Have More than

10,000 Followers $(N=1,119)$

\begin{tabular}{|c|c|c|c|}
\hline Variable & Frequency & $\begin{array}{l}\text { Percentage } \\
\text { of the total }\end{array}$ & $\begin{array}{r}\text { Percentage } \\
\text { who are Italian }\end{array}$ \\
\hline Organization & 325 & $29 \%$ & $49 \%$ \\
\hline Individual & 794 & $71 \%$ & $68 \%$ \\
\hline Male & 616 & $78 \%$ & $69 \%$ \\
\hline Female & 174 & $22 \%$ & $63 \%$ \\
\hline Foreign & 422 & $38 \%$ & - \\
\hline Italian & 697 & $62 \%$ & - \\
\hline Sports, show-business, popular culture, arts & 342 & $33 \%$ & $68 \%$ \\
\hline Journalist/media & 233 & $22 \%$ & $79 \%$ \\
\hline Corporate/consultants & 144 & $14 \%$ & $30 \%$ \\
\hline Politician/party, trade union/unionist & 127 & $12 \%$ & $69 \%$ \\
\hline Blogger/blog & 71 & $7 \%$ & $69 \%$ \\
\hline Technology & 44 & $4 \%$ & $36 \%$ \\
\hline NGOs, public interest groups, social movements & 29 & $3 \%$ & $38 \%$ \\
\hline Political professional, academic & 27 & $3 \%$ & $59 \%$ \\
\hline Satire/comedian & 27 & $3 \%$ & $96 \%$ \\
\hline
\end{tabular}

